\title{
Pterygium and pinguecula: Do the Bengaluru garment factory workers suffer from this eye morbidity?
}

\author{
Harish Kumar $\mathbf{N}^{1}$, Sandhya. $\mathbf{R}^{2, *}$, Sharath B.N. ${ }^{3}$ \\ ${ }^{\mathbf{1}}$ Assistant Professor, ${ }^{2}$ Professor, Dept. of Ophthalmology, ESIC Medical College and PGIMSR, Rajajinagar, Bengaluru, \\ Karnataka, ${ }^{3}$ Assistant Professor, Dept. of Community Medicine, ESIC Medical College and PGIMSR, Rajajinagar, Bengaluru, \\ Karnataka, India
}

*Corresponding Author:

Email: sanchina@rediffmail.com

\begin{abstract}
Introduction: India is a developing country \& the garment workers in these industries are exposed to various occupational health problems, leading to sickness absenteeism and compromise in quality of life, \& the eye disorders were reported by $11.2 \%$ of workers. The prevalence of pterygium in India varies from $9-12 \%$ in general population. This study aims at determining the proportion of garment factory workers suffering from pinguecula and/or pterygium and their associated risk factors.

Methods: It was a cross-sectional study. All the garment factory workers presenting to the ophthalmology department for routine eye examination were screened for pinguecula and pterygium. Standard protocol was followed to measure vision using Snellen's chart. Data was analysed for percentage and proportions after obtaining approval from Institutional Ethics Committee.

Results: A total of 848 subjects were screened out of which $102(12.03 \%)$ were found to have pinguecula or pterygium. Of these $91 \%$ were females and $9 \%$ were males \& the mean age of the affected was 39 years. Pinguecula was present in 84 subjects (82\%) $\&$ pterygium was present in $18(17.7 \%)$ subjects. The nature of work in majority of the subjects $(\mathrm{n}=79,77.5 \%)$ was tailoring. Sickness absenteeism was more profound in pterygium group (28\%). Personnel's with greater than twelve years of work experience had suffered by pinguecula (44\%) and pterygium (39\%).

Conclusion: In our study 1 in 8 workers suffered from pinguecula or pterygium. The affected belonged to middle age (39 years) and had significant work experience (above 12 years). Thus pterygium and pinguecula may be considered as major occupational health problems among the garment factory workers. Immediate policy decisions like screening and providing better working conditions for the workers is the need of the hour for the garment industries.
\end{abstract}

Keywords: Garment workers, India, Pinguecula, Pterygium.

\section{Introduction}

India is a developing country and is more industrialised due to the proliferation of medium and small scale industries in the recent years. These industries pave way to large number of job opportunities to both the skilled and unskilled workers. The textile industry is more progressive and the garment factory workers form a considerable population among all these industries. Currently, the readymade garment industry is a bread earner for more than 33 lakh families and there are more than 33,371 such industries in India. ${ }^{1}$

The Bengaluru city in south India is home for nearly 270 readymade garment factories. The workers in these industries are exposed to various occupational health problems which can range from very mild to severe degree, leading to sickness absenteeism and compromise in quality of life. Most often the gravity of eye morbidity are undermined by the personnel's and they usually attribute it to exposure to fine cotton dust fibre or other dust particles which arise during the processing of garments. The garment workers are known to suffer from eye allergy and dry eye due to prolonged exposure to allergens at work place. ${ }^{2}$ Many studies have reported on health problems in garment workers and dust was perceived as one of the most common physical hazards by $44.5 \%$ of workers at work place and eye disorders were reported by $11.2 \%$ of workers. $^{3}$

All these risk factors including the exposure to ultraviolet light may contribute to the development of pinguecula and pterygium. ${ }^{4}$ The presence of pinguecula or pterygium is an incidental finding during routine eye examination or it may be noticed by self/relatives/friends at times. Many people seek consultation because it results in not only cosmetic blemish and it may extend on to the corneal surface and result in irregular astigmatism and visual impairment. ${ }^{5,6}$ The prevalence of pterygium in various studies conducted in India is about $9-12 \%{ }^{6-8}$

We under took this study to determine the proportion of garment factory workers suffering from pingueculaand/orpterygium and their associated risk factors among the subjects attending Department of Ophthalmology at ESIC Medical College and PGIMSR, Bengaluru.

\section{Methods}

It was a cross-sectional study conducted during November 2017 to January 2018 at Department of Ophthalmology, ESIC Medical College and PGIMSR, Rajajinagar, Bengaluru. The hospital is a tertiary care centre with 750 inpatient beds and caters to nearly five lakh insured people across the city. All the garment factory workers presenting to the department for routine 
eye examination were screened for pinguecula and pterygium. The key variables collected from the informants were age, sex, work experience in the industry, nature/type of work and usage of spectacles.

Ophthalmologic examination: For the purpose of the study two Ophthalmologists and two Optometrists were trained to perform the examination. Standard protocol was followed to measure vision using Snellen's chart. Best corrected visual acuity after refraction was recorded.

The primary outcome variable was presence of pinguecula or pterygium in either of the eyes. The following were the operational definitions of pinguecula and pterygium; (1) Pinguecula is defined as yellowish or greyish white elevated mass of tissue on conjunctiva, ${ }^{9}$ not crossing the limbus. (2) Pterygium is defined as fleshy fibro-vascular mass crossing the limbus usually seen on the nasal side of the conjunctiva. ${ }^{5}$ Data was analysed for percentage and proportions.

Ethical considerations: The Institutional Ethics Committee of ESIC Medical College and PGIMSR, Bengaluru had provided the ethics approval for the conduct of the study. All the participants provided the written informed consent to participate in the study.

\section{Observations}

Table 1: The sociodemographic characteristics of patients with pinguecula and pterygium attending the department of Ophthalmology, ESIC MC and PGIMSR, Rajajinagar. 2017-18

\begin{tabular}{|c|c|c|}
\hline Characteristics & $\begin{array}{c}\text { Pinguecula } \\
\mathbf{N}(\%)\end{array}$ & $\begin{array}{c}\text { Pterygium } \\
\mathrm{N}(\%)\end{array}$ \\
\hline \multicolumn{3}{|l|}{ Age group (years) } \\
\hline $15-25$ & $2(2.4)$ & $0(0)$ \\
\hline $26-35$ & $21(25)$ & $2(11.1)$ \\
\hline $36-45$ & $47(56)$ & $14(77.8)$ \\
\hline $46-54$ & $14(16.7)$ & $2(11.1)$ \\
\hline \multicolumn{3}{|l|}{ Sex } \\
\hline Male & $6(7.1)$ & $3(16.7)$ \\
\hline Female & $78(92.9)$ & $15(83.3)$ \\
\hline \multicolumn{3}{|l|}{ Nature of work } \\
\hline Cutting & $1(1.2)$ & $0(0.0)$ \\
\hline Embroidery & $0(0)$ & $1(5.6)$ \\
\hline Helper & $2(2.4)$ & $1(5.6)$ \\
\hline Ironing & $3(3.6)$ & $0(0)$ \\
\hline Operator & $2(2.4)$ & $1(5.6)$ \\
\hline Packing & $2(2.4)$ & $2(11.1)$ \\
\hline Quality check & $5(6.0)$ & $1(5.6)$ \\
\hline Sorting & $0(0)$ & $1(5.6)$ \\
\hline Tailor & $69(82.1)$ & $10(55.6)$ \\
\hline Washing & $0(0)$ & $1(5.6)$ \\
\hline \multicolumn{3}{|l|}{ Onset } \\
\hline 0 to $<6$ months & $20(23.8)$ & $4(22.2)$ \\
\hline 6 to $<12$ months & $22(26.2)$ & $2(11.1)$ \\
\hline$\geq 12$ months & $42(50.0)$ & $12(66.7)$ \\
\hline \multicolumn{3}{|l|}{$\begin{array}{l}\text { Sickness } \\
\text { absenteeism }\end{array}$} \\
\hline No & $75(89.3)$ & $13(72.2)$ \\
\hline
\end{tabular}

\begin{tabular}{|l|c|c|}
\hline Yes & $9(10.7)$ & $5(27.8)$ \\
\hline $\begin{array}{l}\text { Consultation } \\
\text { availed }\end{array}$ & & \\
\hline Public & $14(16.7)$ & $8(44.4)$ \\
\hline Private & $16(19.0)$ & $3(16.7)$ \\
\hline Not availed & $54(64.3)$ & $7(38.9)$ \\
\hline Work Experience & & \\
\hline 0 to $<6$ years & $17(20.2)$ & $5(27.8)$ \\
\hline 6 to $<12$ years & $30(35.7)$ & $6(33.3)$ \\
\hline$\geq 12$ years & $37(44.0)$ & $7(38.9)$ \\
\hline
\end{tabular}

\section{Results}

During the study period, a total of 848 subjects were screened out of which $102(12.03 \%)$ were found to have pinguecula or pterygium; among those affected nearly $91 \%$ were females and $9 \%$ were males. The mean age of the affected was 39 years (SD: 5.9; range $22-53$ years). The sociodemographic characteristics are shown in Table 1.

Pinguecula was present in either eye of 84 subjects (82\%), of which $6(7 \%)$ subjects were males and 78 (93\%) subjects were females; pinguecula was present in both eyes in 65 subjects (mean age $=39$, SD: 6.3) and in one eye of 19 subjects (mean age=37.4, SD: 5.8).

Pterygium was present in either eye of $18(17.7 \%)$ subjects (mean age 39, SD: 4.2), of which 3 (17\%) were males and $15(83 \%)$ were females, pterygium was present in both eyes of 16 subjects (mean age 39, SD: 3.3 ) and in one eye of 12 subjects (mean age 39 years, SD: 4.8).

The nature of work in majority of the subjects $(\mathrm{n}=79,77.5 \%)$ was tailoring. Most of them noticed Pterygium earlier $(\mathrm{n}=12,66.7 \%)$ than pinguecula $(n=42,50 \%)$. Sickness absenteeism was more profound in pterygium group (28\%) than in pinguecula group (11\%) and was found to be statistically significant. Most of the subjects (61\%) had availed consultation either at public $(44 \%)$ or private $(17 \%)$ health facility. Personnel's with greater than twelve years of work experience had suffered by pinguecula $(44 \%)$ and pterygium (39\%). The newly diagnosed subjects with refractive error were more in the pterygium group $(56 \%)$ than in pinguecula group (32\%) and was found to be insignificant. No cases suffered or had visual impairment because of pterygium. None of the factors were found to be statistically significant across the groups.

\section{Discussion}

It is one of the first study conducted to determine the proportion of garment workers suffering from pterygium or pinguecula; our study findings revealed that 1 in 8 workers suffer from this eye morbidity. This high proportion of morbidity seems to be a serious occupational health hazard among the garment factory workers. The affected population mainly belongs to middle age group (39 years) and who had significant 
work experience in this field (above 12 years). The majority of the affected population worked as tailors.

Many a times pterygium was noticed earlier by subjects when compared to pinguecula; mainly because it is more prominent and easily noticed by others. It is also prone for recurrent inflammations and is associated with dryness of eyes which is more symptomatic. As a result, most of the subjects had sickness absenteeism when compared to pinguecula.

Most of the subjects did not avail any consultation $(60 \%)$ as they were asymptomatic. Of the few who availed consultation majority accessed public health facility than private health facility. All the workers were covered under ESIC social security scheme under which they were entitled to avail free medical and surgical care, the scheme is considered as one of the best social security scheme available in the country. When enquired it was noticeable that the trust factor of these subjects on the care providers at public facility was good and also the quality of care provided at these facilities was satisfactory. Those who went to private facility went due to lack of time to visit public facility and close location to their residence.

Apart from the eye morbidities the garment factory workers also suffer from respiratory diseases. Most of the times the respiratory disease are attributed to cotton dusts that could act as allergen which would lead to acute and chronic respiratory diseases.

\section{Conclusion}

Pterygium and pinguecula are major occupational health problems among the garment factory workers. Diligent policy decisions like screening and providing better working conditions for the workers is the need of the hour for the garment industries.

Though, the newly diagnosed refractive errors were more in the pterygium group $(56 \%)$ than pinguecula group $(32 \%)$ it was found to be statistically insignificant. As described elsewhere, pterygium grows onto the cornea from conjunctival side while it encroaches the cornea it leads to flattening of corneal curvature in that meridia and thus changes the effective power of the cornea in that meridia which leads to astigmatism. The subjects in their presbyopic age usually opt for presbyopic glasses as their work demands closer and prolonged focus as they had to look at finer details. None of the patients in this study had work related eye injury or blindness.

The proposed key recommendations for the garment industries are to (a) maintain good ventilation practices at the working areas (b) regular screening of the garment workers every six months (c) adopt rotational policy for the workers based on the nature of work they perform (d) provide suitable protective eye wears against exposure to allergens.

The strengths of our study was that all the participants had worked in garment industries and were attending the department of Ophthalmology for some ailments. The limitation was that we were not able to ascertain the working environment at the factories to establish a cause effect relationship. An effort must be made ascertain sickness absenteeism of the garment workers attributable to eye morbidity by review of records, which may help in making policy decisions regarding occupational eye health.

\section{Conflict of Interest: None}

\section{References}

1. MS Kumari, MR Bassanna; Readymade Garment Industry in Bangalore City - A study with special reference to problems associated with Production. Acme Intellects International Journal of Research in Management, Social Sciences \& Technology. Vol- 9 No. 9 Jan 2015;ISSN 2320-2939 (Print).

2. Ali Abdullah Taqi, Omar O. Abdullah. The Frequency of Pterygium and Dry Eye in Chronic Cement Exposure: A Clinical Case-Control Study. Int J Med Res Prof. 2016;2(5);40-44.

3. S Khandker, SKA Ahmad, MH Khan, MhFaruquee et al. Perceived workplace hazards and Health problems among the workers of Garment Factory in Dhaka. JOPSOM, 2016;35(2):1-9.

4. Chao SC, Hu DN, Yang PY, et al. Ultraviolet-A irradiation upregulated urokinase-type plasminogen activator in pterygium fibroblasts through ERK and JNK pathways. Invest Ophthalmol Vis Sci. 2013;54:999-1007.

5. Srinivas Marmamula, Rohit C. Khanna, Gullapalli N. Rao; Population-Based Assessment of Prevalence and Risk Factors for Pterygium in the South Indian State of Andhra Pradesh: The Andhra Pradesh Eye Disease Study. Invest. Ophthalmol. Vis. Sci. 2013;54(8):53595366.

6. Durkin SR, Abhary S, Newland HS, Selva D, Aung T, Casson RJ. The prevalence, severity and risk factors for pterygium in central Myanmar: the Meiktila Eye Study. Br J Ophthalmol. 2008;92:25-29.

7. Nangia V, Jonas JB, Nair D, Saini N, Nangia P, et al. (2013) Prevalence and Associated Factors for Pterygium in Rural Agrarian Central India. The Central India Eye and Medical Study. PLoS ONE 8(12): e82439. doi:10.1371/journal.pone.0082439.

8. Asokan R Venkatasubbu RS Velumuri L Lingam V George R. Prevalence and associated factors for pterygium and pinguecula in a South Indian population. Ophthalmic Physiol Opt. 2012;32:39-44.

9. https://www.aao.org/eye-health/diseases/pingueculapterygium. 